\title{
WHO IS THE FACIALSPECIALIST? HYALURONIC ACID FILLERS: OPTIMISATION OF AESTHETIC DENTISTRY AND PATIENT LOYALTY
}

\author{
Aldo Zupi ${ }^{1 a^{*}}$ \\ 'Libera Università Internazionale del Benessere, Rome, Italy \\ aMD, DDS, MSci, PhD
}

Received: August 24, 2016 Accepted: August 25, 2016 Available online: September 07, 2016

Cite this article:

Zupi A. Who is the facial specialist? Hyaluronic acid fillers: optimisation of aesthetic dentistry and patient loyalty. Stoma Edu J. 2016;3(2):168-177.

\section{ABSTRACT}

The hyaluronic acid is the most used filler for the correction of facial wrinkles. The filler procedure is relatively painless and virtually free of complications and side effects. It requires deep knowledge of the face anatomy and its tissues, understanding of the skin physiology, excellent knowledge of injection techniques, ability to empathise with the patient and aesthetic sensibility. Dentists are the most facilitated specialists in this field. They have great knowledge of facial anatomy with its skeletal, muscular, vascular and nervous structure and, in addition, they master, better than anyone else, the injection technique.

Face and smile are indivisible units. No facial aesthetic treatment would be completely satisfactory if it did not involve the care of the teeth and smile. The clinical approach proposed here aims to gain the tools to integrate the examination of the soft tissue of the face, with their anatomic and functional characteristics, in the dentists' routine. Through this approach we can decode, simplify and make possible the harmony, complex and unique, of the faces of our patients. The final aim is to increase the services and the therapeutic options offered with the integration of perioral soft tissue treatment protocol to common approach to classic dentistry.

Keywords: Esthetic, Dental; Dermal fillers; Hyaluronic acid

\section{Introduction}

The analysis that each one of us performs in the clinic routine highlights the aspects that we know we can improve with the old or new techniques at our disposal. When we look at someone's face, we focus on some details based on our profession, our passion and sometimes, our desires. A hairstylist will be driven to observe the quality of a haircut, for instance. In the same way, a make-up artist will evaluate the way in which someone is wearing make up. Instinctively, she will think what product that person used and how good it is and if it suits the subject. A stylist will notice the accessory and clothes a person is wearing. He might even judge the taste of that person.

A dentist, who loves his job, will always focus his attention to someone's smile and mouth. He will start thinking of a treatment for that person. Moreover, the facial analysis performed by the prosthodontics is different from the one performed by the dentist and different from what the maxillofacial or plastic surgeon analyse. Still different, it is the analysis performed by dermatologists or medical aesthetics. This confirms the phrase: "what we see depends mainly on what we look for"1. Our eyes look for what we desire and they only see what we are able to understand. John Lubbock said that. He was a banker, liberal politician, philanthropist and scientist. He was influential in the nineteenthcentury's debates concerning evolutionary theory $^{2}$. This quote is very appropriate for our case, because "what we see depends on what we can offer to the patient".

To improve the aspect of a person, dentists are always able to evaluate the quality of the teeth alignment and eventually propose almost invisible dental treatments. Also, decayed or damaged teeth can be cured or replaced. Whitening treatments are always more efficient and less aggressive on the teeth. It is time for the dentist to start working on the frame of the smile too, which makes it healthy and beautiful. The patient often implicitly requires this. Sometimes, however, the patient makes this request explicitly. So, as dentists, we cannot say no! It is a duty and also an opportunity for us.

Patients, more often now, ask for rejuvenation injection procedures for their face. At the end of the nineties, the majority of patients who asked for an aesthetic treatment preferred surgical procedures (more than 55\%) ${ }^{3}$. Now, this balance is completely inverted. In 2015, slightly less than $90 \%$ of patients

\section{*Corresponding author:}

Aldo Zupi, MD DDS MSci PhD.Via Zabarella 64, 35122 Padova, Italy

e-mail:zupiland@hotmail.com 


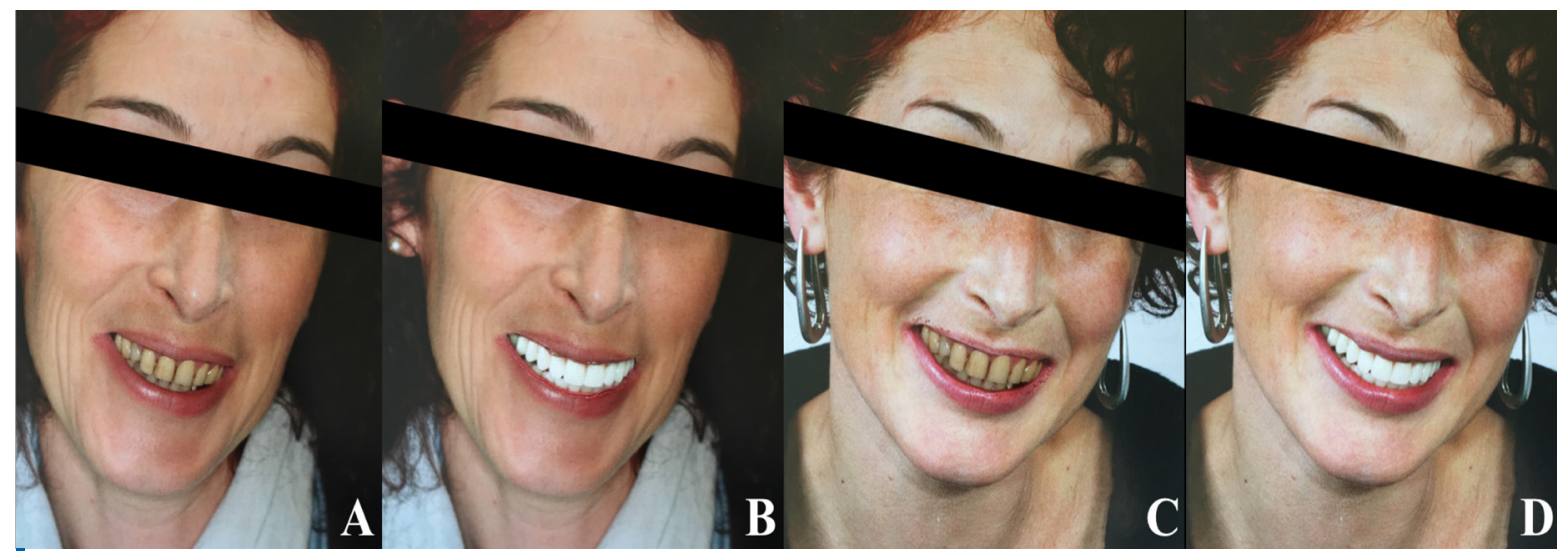

Figure 1. Simulation of the treatment on the same patient $(A)$ by different specialists. Traditional dental treatment without HA fillers (B). Treatment with HA fillers without any dental intervention (C). Combined treatment of aesthetic dentistry and HA filler. (D). N.B. Images (A) and (D) are real, images (B) and (C) have been created by the combination of the first two.

Modified from: Costa $\mathrm{E}$ (ed). Estetica dei tessuti orali e periorali in odontoiatria. Parma, Italy: Acta Medica Edizioni; 2014. Courtesy of the author

in the United States strongly preferred injectable or minimally invasive procedures ${ }^{4}$. The percentage increases for facial rejuvenation: more than nine million people, only in the United States, have chosen facial filler and botulinum ${ }^{4}$. The facial rejuvenation procedures with dermal filler (together with botulinum) represent the area of higher growth in cosmetic treatments. In the United States alone, in 2015, patients have paid over 1.6 billions of dollars for facial fillers ${ }^{4}$.

The increase in demand of this kind of treatment also increased the number of practitioners who offer this service. This meant that a lot of new figures entered this area of expertise that were not traditionally involved in it. The dermal filler procedure in general, and facial filler in particular, initially neglected by plastic surgeon because it was considered minor, has now become a land to conquer by many specialists. Dermatologists in primis; followed by gynaecologists, anaesthesiologists and so on: clinicians and nonclinicians ${ }^{5}$. And last, dentists, who finally decided to enter this area. However, still today, with differences from country to country, dentists hesitate to join this area.

The most of us in the dental industry are quite ignorant of what these procedures even are, the theories behind them, the way they are delivered and the benefits for the patients. The aim of this paper is to gain the tools to integrate the examination of the soft tissue of the face, with their anatomic and functional characteristics, in the clinical routine, following a simple and well-tested protocol. In this way, dentists will be able to extend their view of the characteristics of a smile and a face and to propose innovative therapeutic solutions, which will meet the patient's request and expectations.

\section{Hyaluronic acid: what it is, where and how it works}

The hyaluronic acid (HA) is the most used filler for the correction of wrinkles, skin imperfections and the remodelling of the face $e^{6,7}$. HA is a substance normally found in the skin and it gives its characteristics of resistance and maintenance of the form ${ }^{8}$. With age, the physiological production of $\mathrm{HA}$ decreases and the skin loses elasticity and tone; this is what determines the creation of expression lines and wrinkles $6,7,9$.

The HA is a glycosaminoglycan, which consists of regular repeating non-sulfated disaccharide units of glucuronic acid and $\mathrm{N}$-acetylglucosamine ${ }^{8}$. Binding to many water molecules, the HA gives hydration, elasticity and softness of the tissues, protecting them from excessive solicitations ${ }^{6,7,9}$. The concentration of HA in the connective tissue of the skin gets gradually reduced with time. For this reason, a mature skin appears less elastic and hydrated compared to younger skins. Although it is a normal physiologic phenomenon, many people want to fight the advancing age, therefore prevent wrinkles and other skin imperfections.

$\mathrm{HA}$ fillers were developed at the end of the eighties ${ }^{10}$. They represent an efficient minimally invasive solution for the imperfections of the face mainly caused by the aging of the skin, but also "congenital"7. The infiltrations can be performed alone or as a completion of a plastic surgery operation such as lifting. With the injection of HA intradermal the filling of the wrinkles and the increase of the volume of the face is achieved.

There are different types of HA filler with different characteristics. The HA does not have side effects, it does not require an allergy test, gives a natural modelling to the treated area and it gets gradually absorbed in a few months (from four to twenty-four months $)^{6,7,9,11}$. The time of reabsorption depends on different factors. The most important ones are the type of skin, the treated area, tobacco use, eating habits, overexposure to UV rays (both natural and artificial) the quantity and the density of the injected filler ${ }^{7,11}$.

HA fillers are injected intradermally with pre-measured syringes and thin needles (from 20 to 30 gauge). 


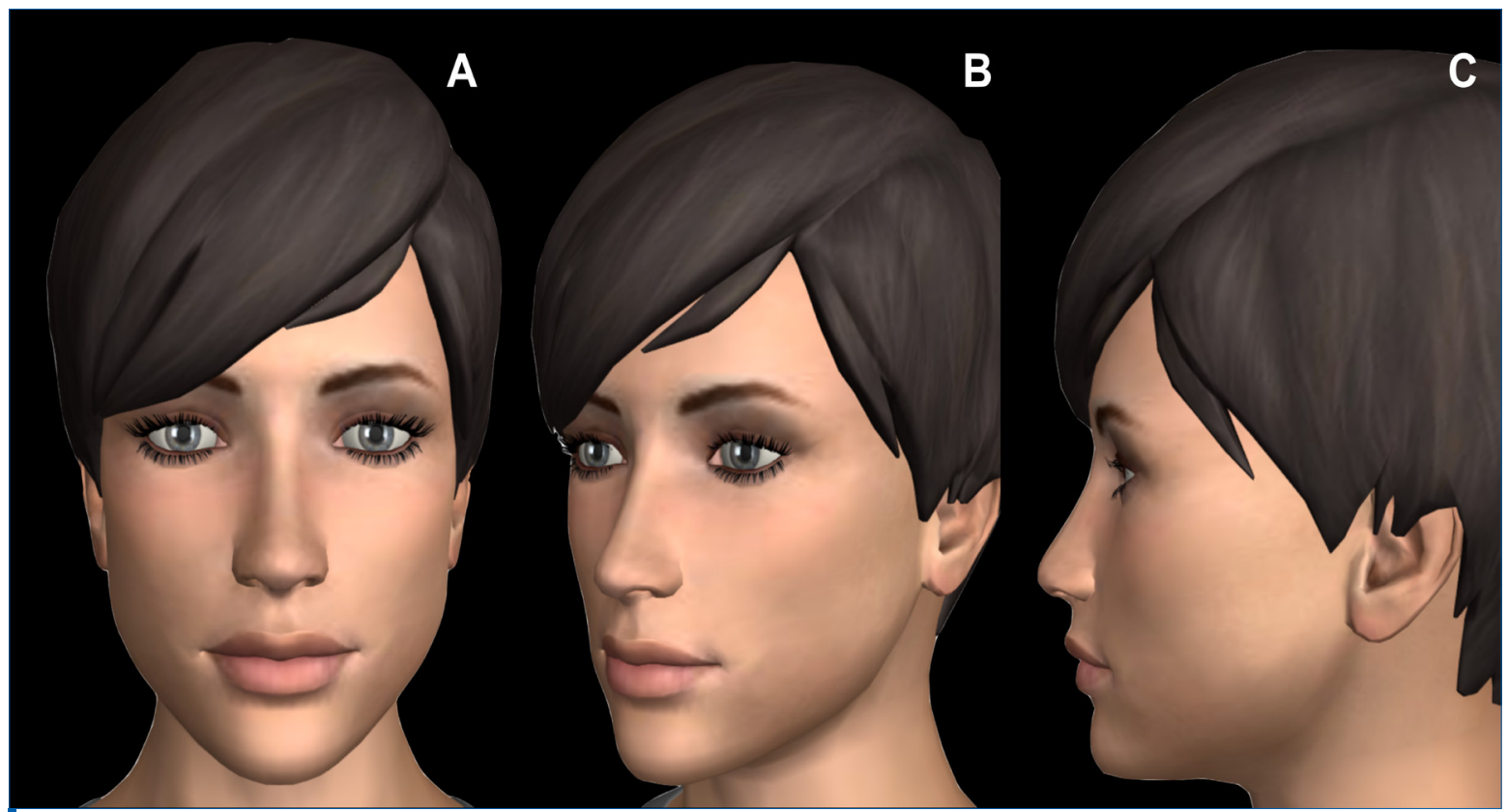

Figure 2. Facial proportion analysis. Soft tissue examination is performed in the three projections: frontal (A), oblique (B) and lateral view (C). The patient should be evaluated standing up with his head in a natural head position, with the eyes staring at a point to the horizon on the same plane of his or her eyes.

Drawn by Aldo Zupi using ZygoteBody ${ }^{\mathrm{TM}}$ 3D Anatomy Viewer. Zygote Media Group Inc., American Forks, UT

Contraindications are rare: skin diseases, infections or viruses (e.g. herpes labialis) in progress, autoimmune diseases of the skin and collagenopathies ${ }^{12}$. Although there is no evidence of contraindication, it is safer not to administer HA fillers during pregnancy and breastfeeding ${ }^{12}$.

\section{Who is the facial filler specialist?}

The first objection raised from the dentist (about filler procedure) is always the same: "can the injection technique be done in a dental clinic?" or "wouldn't it be better if specialists such as dermatologists and plastic surgeons did the facial filler?" Surely, from an historical point of view, dermatologists and plastic surgeons have been the first to focus and take care of people's faces and use therapies (more or less invasive) for the maintenance and the recovery of the health and beauty of the patients. In the last years, minimally invasive procedures (such as fillers) started to spread around and different professional categories such as anaesthesiologists, medical aestheticians, ophthalmologists, internists and so on, started to be interested and so they also begun to use facial fillers in their every day practice. In some cases, the filler practice left the medical area to cross into the paramedical area (in the best case scenario). It is not rare that non-medical staff performs procedures such as filler, botulinum, sclerotherapy, and mesotherapy ${ }^{5,13}$.

Usually, the training for these procedures is only focused on the technical aspects. Teaching focuses on just a few concepts. They are surely important, but, perhaps, not enough to create the facial filler specialist. Many facial filler courses are focused on "where", "how much" and "how" to inject. They offer a very quick refresh of our facial anatomy knowledge and of its critical and dangerous areas. The whole aging physiology is discussed rapidly in a couple of sentences. This is enough to gain all the necessary techniques for the surgical procedure. However, they give the necessary anatomical and functional knowledge for granted.

A dentist, any dentist, has spent his whole professional training (from the first day at university) studying and mastering the anatomy and physiology of the oral and perioral area. They have studied and mastered all the aspects and they know the characteristics better than any other medical specialist. In addition, the dentist is the only specialist who spends every day of his profession working on this area, dealing with its singularities and the changes that happen with time. If this were not enough, everything is subject to the aesthetic judgement of the patient every single day.

Therefore, dentists have to accept the ugly truth of being the 'real' specialists of the oral and perioral region (or rather from the chin to the cheekbones) and that their very specific scientific background and their daily work is not comparable to that of any other specialist's. No dermatologist, plastic surgeon or other, will be as competent and confident as the dentist.

With increasing frequency, patients ask us, or our colleagues, for a generic improvement of their physical conditions (Fig. 1A). In these cases, usually, the approach is different depending on the specialist. If the interlocutor is a traditional dentist, the operation will be limited to the teeth and mouth. A traditional dentist sees the patient ex- 

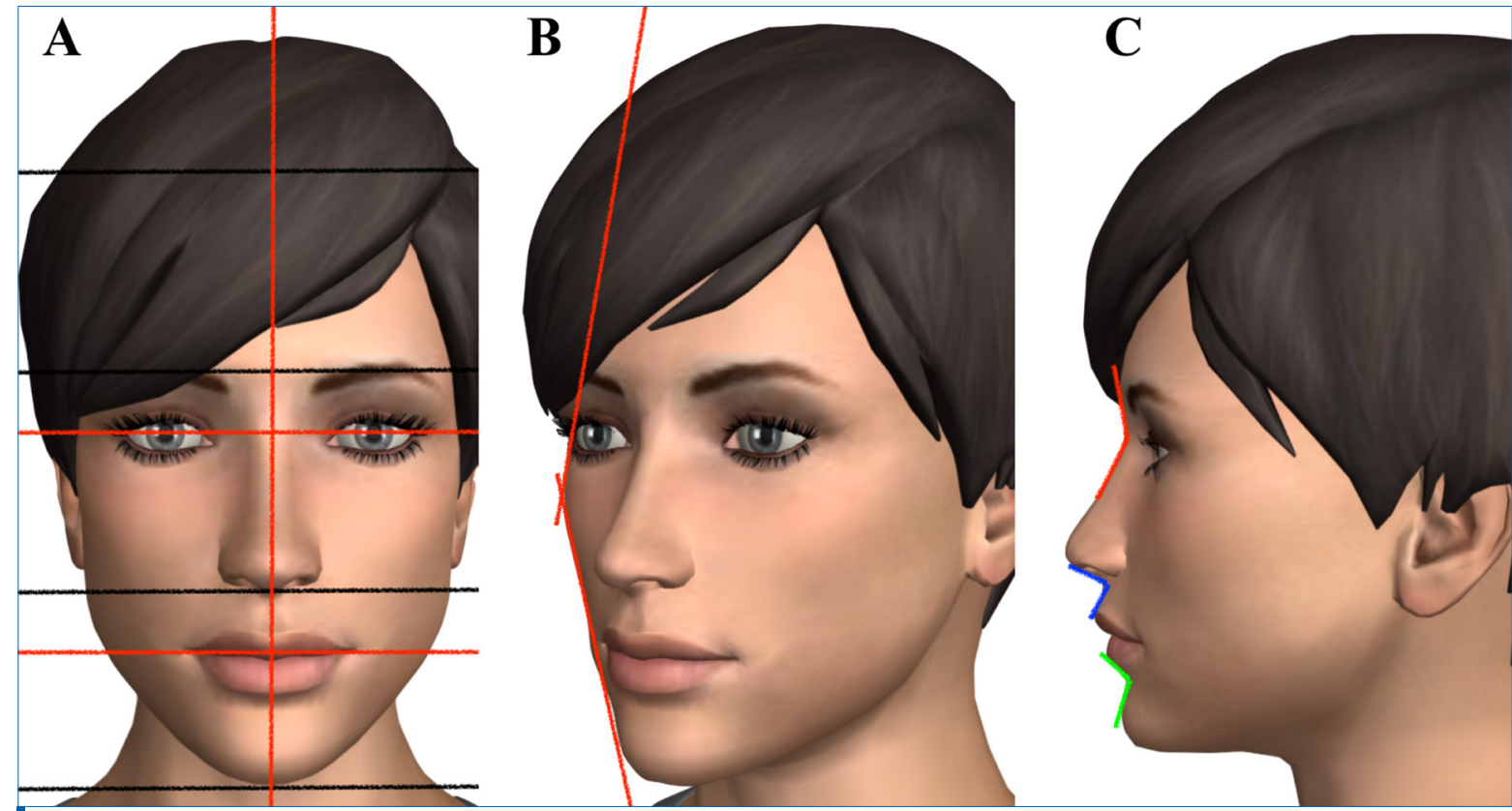

Figure 3. Facial proportion analyses. Frontal view (A). The face is divided into three thirds (black lines): the upper third (in between the hairline and the line which links the upper points of the eyebrows); the middle third (in between the line which links the upper points of the eyebrows and the inter-alar line); and the lower third (from the inter-alar line to the chin). The three thirds should have similar dimensions. More several planes (red lines) should be used as reference points to evaluate the shape (bitemporal, bipupillare, bizygomatic, bigoniale, and inter-commissural line), and the vertical symmetry (vertical median line, intercantal line, and inter-commissural line). Oblique view (B). The face is focused at about $45^{\circ}$ to highlight the angle formed by the buttress of the zygomatic bone on the external profile (red lines). From the internal profile, we will examine the look of the temporal area, of the periorbital area, of the cheek and the definition of mandibular angle. Profile view (C). Several angles can be analysed: the fronto-nasal (red); the naso-labial (blu), it shows if the tip of the nose is facing down and it gives us information on the form of the upper lip; the labio-mental (green) it describes the direction of the labiomental sulcus and allows us to evaluate the form of the lower lip.

Drawn by Aldo Zupi using ZygoteBodyTM 3D Anatomy Viewer. Zygote Media Group Inc., American Forks, UT

clusively as a mouth with teeth and gum. Nothing else. He will most certainly do an excellent job. The patient will definitely be satisfied (Fig. 1B). If the patient went to an aesthetic doctor or plastic surgeon, the evaluation would be very different. Any other doctor, not an odontologist, would not evaluate the mouth. Teeth would be excluded from any kind of evaluation immediately. The exam would concentrate on the skin and face. In this case, too, the plastic surgeon would do a great job and the patient will be satisfied (Fig. 1C). What is the difference you can give to the patient? The difference is a complete exam of the face and the smile and a global and harmonious solution (Fig. 1D).

Face and smile are indivisible units. No aesthetic treatment would be completely satisfactory if it did not involve the care of the teeth and smile. Surely, two or three different specialists can do this separately: dentist and aesthetic doctor; or dentist, aesthetic doctor and plastic surgeon. This is how it used to happen, until now. However, a new kind of dentist with aesthetic sensibility, can finally become the specialist who treats face and smile in a coherent and harmonious way. To be able to do so, a correct and targeted assessment of the patient and serious dermal filler training is required.

\section{Patient's assessment}

The traditional dentistry approach to the solution of cases with aesthetics problems basically consists in the assessment of the beauty of the face based on the personal work experience of each dentist. The main element to assess it is the smile. For the construction of a correct aesthetic plan the face has to be considered in its entirety and it is necessary to have a detailed knowledge of anatomic and functional characteristic of the soft tissue of the face and therapeutically available options for the soft tissue treatment, with a particular reference to possibilities and limits of not surgical techniques ${ }^{14}$.

In the approach to the facial aesthetic rehabilitation, we need to start from the evaluation of several facial parameters: face's form; aspect and position of soft tissue (nose, lips, chin, etc.) and supporting structures (bones, cartilages, and teeth); muscles activity; and aging, meaning the way in which these tissues aged or will age ${ }^{14}$. Leaving out any of these aspects can only take us to a partial aesthetic success without a harmony of the whole face ${ }^{14}$ The integration of perioral soft tissue treatment ex- 
Table 1. Facial analysis. Main elements to evaluate during skin analysis

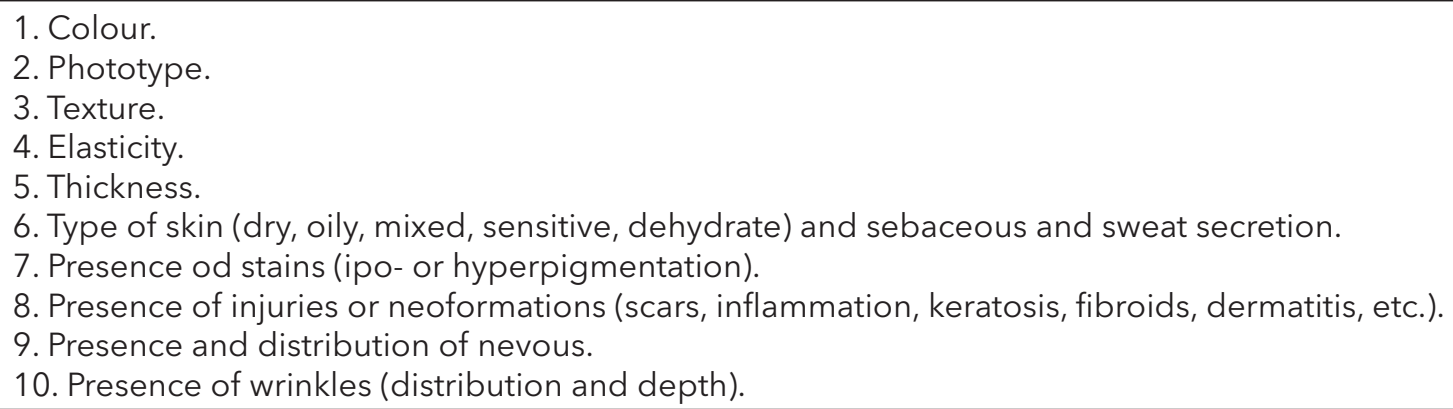

Table 2. Glogau's aesthetic and anatomic analysis of the aging skin

\begin{tabular}{|c|c|c|}
\hline Type I & $\Rightarrow$ & $\begin{array}{l}\text { No wrinkles. Patient age 20-30. } \\
\text { Early photo aging (mild pigmentary changes, no keratosis); minimal acne scarring; need } \\
\text { minimal or no make-up. }\end{array}$ \\
\hline Type II & & $\begin{array}{l}\text { Wrinkles in motion. Patient age } 30-40 \text {. } \\
\text { Early to moderate photo aging (early senile lentigines visible, keratoses palpable but not visible, } \\
\text { parallel smile lines beginning to appear); mild acne scarring; need some foundation. }\end{array}$ \\
\hline Type III & & $\begin{array}{l}\text { Wrinkles at rest. Patient age 50-60. } \\
\text { Advanced photo aging (obvious dyschromia, visible keratosis, discoloration with telangiectasia, } \\
\text { wrinkle present even when not moving); acne scarring present that make-up does not cover; } \\
\text { need heavier foundation. }\end{array}$ \\
\hline Type IV & & $\begin{array}{l}\text { Only wrinkles. } 60 \text { or older. } \\
\text { Severe photo aging (yellow-grey skin colour, prior skin malignancies, wrinkles throughout, cutis } \\
\text { laxa of different origin); severe acne scarring; cannot wear make-up because it cracks. }\end{array}$ \\
\hline
\end{tabular}

amination to classic dentistry approach allows and simplifies the comprehension of the complex and unique harmony of the faces of our patients ${ }^{14}$.

Costa and Di Gioia ${ }^{14}$ have proposed a simple but complete and exhaustive facial analysis protocol. It is the collection of all the information we gained by observing the patient during a clinical examination and by examining photos and videos of the face. This analysis consists in three phases: (A) analysis of facial proportions; (B) skin analysis; and (C) analysis of the expressive quality of a face ${ }^{14}$.

\section{Analysis of facial proportion}

Analysis of facial proportions must consider soft tissue (skin, muscles, subcutaneous fat, intraoral soft tissue) and hard tissue (bone and dental support, dento-alveolar relationship). One must gath- er as much information as possible about the form, the proportions and the symmetries of the face must be gathered. According to Yarbus' studies ${ }^{15}$, when we observe a face, our eyes focus on areas of the face known as Region of Interest. They are the areas of maximum curvature of the face, where the transition between these different areas happens. It is necessary to concentrate our attention on these areas.

We practice the soft tissue examination in the three projections: frontal, oblique and lateral view (Fig. $2)$. In the same projections we will perform a series of aesthetic photos of the face. The patient should be evaluated standing up with his head in a natural position meaning with the eyes staring at a point in the horizon on the same plane as his or her eyes. The best point of view is given when the head pos- 
Table 3. Characteristics of the dermal filler with hyaluronic acid procedure

\begin{tabular}{|c|c|}
\hline Duration of the procedure. & From five to fifteen minutes. \\
\hline $\begin{array}{c}\text { Necessity of post-treatment observation. } \\
\text { Type of treatment. }\end{array}$ & $\begin{array}{c}\text { Until one hour from the treatment. It does not require particular environment (it can } \\
\text { be done in the waiting room). }\end{array}$ \\
\hline $\begin{array}{c}\text { Necessity of post-treatment medications. } \\
\text { Local infiltration (hyaluronic acid) absolutely biocompatible. }\end{array}$ & $\begin{array}{c}\text { No medication. Useful post-treatment check to evaluate the result and eventual } \\
\text { 'touch up'. }\end{array}$ \\
\hline $\begin{array}{c}\text { Inability period or post-treatment } \\
\text { convalescence. }\end{array}$ & $\begin{array}{c}\text { None. It is possible to resume activities immediately after the operation (lunch-time } \\
\text { treatment). }\end{array}$ \\
\hline $\begin{array}{c}\text { Post-treatment outcome. } \\
\text { none. The injection does not create any scars and the complete absorption of the hyal- } \\
\text { uronic acid does not create outcome. Complications are very rare (usually self-limiting). }\end{array}$ \\
\hline
\end{tabular}

ture respects the parallelism between the Frankfurt plane and the horizon. We will be looking for the same posture of the head in all the other projections as well.

In the frontal view we will divide the face in three thirds: the upper third, in between the hairline and the line which links the upper points of the eyebrows; the middle third, in between the line which links the upper points of the eyebrows and the inter-alar line; and the lower third, from the interalar line to the chin (Fig. 3A). We can now evaluate the proportions between the three thirds, which should have similar dimensions.

In the frontal view we also identify several lines, which will be used as reference points (Fig. 3A). Some of them (bitemporal, bipupillar, bizygomatic, bigonial) can be used to evaluate the shape of the face. The form of the face can vary a lot from one patient to other. This is an important parameter to take into account as the patient's request could modify the form of his or her face. Sometimes, the patient will ask to soften the curves of the face or to emphasise some characteristics. We will have to verify the parallelism between these lines and the inter-commissural line. An eventual lack of parallelism between the inter-commissural line and the horizontal lines of the face should also consider an accurate dental occlusion evaluation.

Using the frontal view again, the symmetry of the face can be analysed. Let us draw the vertical plane (a median line of the face passing through the centre of the glabella and the centre of the upper lip philtrum); let us examine the deviations, the asymmetries, the deviation of the tip, and dorsum of the nose (Fig. 3A). With the comparative analyses of the two hemifaces, it is possible to immediately detect eventual asymmetries without being influenced by the mimic.

The second projection is the oblique one (Fig. $3 B$ ). In the oblique view we can focus on the face at about $45^{\circ}$ to highlight the angle formed by the buttress of the zygomatic bone on the external profile, which with young women is projected upwards: it is also known as malar projection angle, it becomes more evident with age as it gets smaller and the zygomatic buttress gets lower. From the oblique projection, we will examine the look of the temporal and periorbital area, of the cheek and mandibular angle. These areas, too, lose tone and tend to fall with time. Moreover, we can observe the form and the dimensions of the nose and its relationship with the philtrum.

The third projection is the profile (Fig. 3C). The division of the face in three thirds, as in the frontal view, gives us information concerning the facial height, especially about the lower third of the face. On the profile we analyse several angles: the fronto-nasal angle $\left(115^{\circ}-130^{\circ}\right)$; the naso-labial angle $\left(85^{\circ}-105^{\circ}\right)$, it shows if the tip of the nose is facing down and it gives us information on the form of the upper lip; the labio-mental angle $\left(110^{\circ}-130^{\circ}\right)$, which describes the direction of the labio-mental sulcus and allows us to evaluate the form of the lower lip ${ }^{14}$

A profile is defined as concave (common in the elder patients or edentulous patients) if the angle formed at the intersection of the line drawn from the glabella to the sub nasal point with the line from the sub nasal point to the cutaneous pogonion is bigger than $180^{\circ}$ or convex if the corner is smaller than $180^{\circ}$. This angle gradually changes with age. It becomes increasingly wide until it reaches figures such as $200^{\circ}$ in edentulous older patients.

Once the proportions of the face have been studied as a whole and we have an idea of the unbalanced areas, we can observe the aesthetic regions of the face, following a useful medical division of these parts (Fig. 4); we can now examine each of these areas and each area's relation to the others, to identify the ones, which may need intervention. The lips and the perioral region represent the main areas of aesthetic intervention for the dentist. Therefore, very deep knowledge of its biological and anatomic characteristics of it is required. We will evaluate form, dimension, volume, tone and symmetry of the upper and inferior lip. We will observe the relationship between the upper and inferior lip (ideally it varies from 1:2 in favour of the lower lip's height). It is necessary to respect these characteristics even after the corrections, on both intra and extra-oral level, to preserve a natural look. The lip and perioral region is subdivided into at least ten sub-regions with very different characteristics from one another, which require different ways of therapeutic approach (Fig. 5). Each one of 


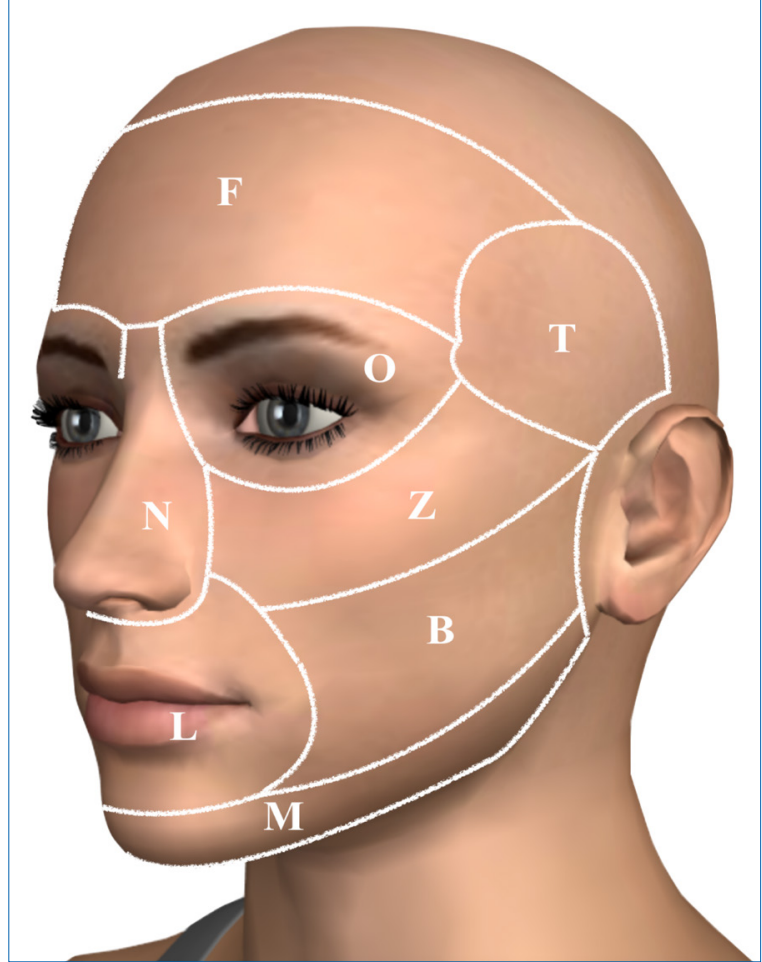

Figure 4. Aesthetic regions of the face. The main aesthetic regions of the face are: the frontal region $(F)$, the temporal region $(T)$, the orbital region $(\mathrm{O})$, the zygomatic region $(\mathrm{Z})$, the buccal region $(B)$, the nasal region $(N)$, the mandibular $(\mathrm{M})$, and the lip and perioral region (L).

Drawn by Aldo Zupi using ZygoteBody ${ }^{\mathrm{TM}}$ 3D Anatomy Viewer. Zygote Media Group Inc., American Forks, UT

these areas has particular anatomic features: skin, subcutaneous tissues, muscles, fat, movements and mimic. The therapeutic options will be different for each different area. In addition, we need to consider the changes associated to aging and this allows us to understand how important it is to know the face anatomy before any intervention. Careful attention must be paid to the exterior margin of the vermilion. It is surrounded by a thin line and slightly detected skin called the lip white roll (Fig. 5). It is very noticeable in young lips, which highlights the red border of the lip. The presence of this area is one of the secrets best kept by plastic surgeons. Its presence and its use allow as to obtain excellent aesthetic results with no invasive treatment.

\section{Skin analysis}

The next step is the skin analysis: a glowing and well-maintained skin improves the beauty of a face and a smile. We need to be able to do an initial screening of the status of the skin and eventually we need to be able to spot injuries or diseases, which will be evaluated by the dermatologist. It is important to asses the skin surface. We will examine as many elements as possible (Tab. 1). Hair, eyebrows, eyelashes, colours of the eyes and make up are considered characteristics, which are perceived as parts of a person's personality. When the main physiological parameters of function get closer to 'normality' the skin will look bright, light, compact, well hydrated, soft, elastic and smooth. An important parameter to evaluate in the analysis of the skin is the texture (also called webbing or skin profile). The skin texture is formed of the set of lines, which fused together on the skin surface surround quadrangular or rhomboid areas with primary and secondary lines. It is very hard to observe this in children and babies with a naked eye. With age, these lines become less frequent, deeper and messy. The skin texture can be evaluated through macrophotography according to Beagley and Gibson ${ }^{16}$ or through profilometry ${ }^{17}$ and it is conditioned by the form and function of the structures, which cover it.

The skin examination is obviously completed with the observation of wrinkles. A good reference for this evaluation is the classification of $\mathrm{Glogau}^{18}$, which links age, wrinkles and texture quality (Tab. 2 ). To be able to understand the difference between the wrinkles and the rationale of their treatment it is necessary to remember the structure of the skin.

The skin of the face is a layered structure. The main layers are the epidermis and the dermis. Below them there is the adipose tissue. The depth of these layers gradually varies depending on the area of the body and face examined. It is very thin in the periocular region; it becomes thicker on the cheeks, it gets thinner again on the mandibular region to then become once again thicker in the perioral region. The epidermis is subdivided in a keratinized superficial portion with the cellular elements at the end of its life cycle and in a deeper portion with vital cellular elements. In the deepest zones of this layer the melanocytes have been localised, which explains the difficulties in treating the skin spots. Below the epidermis, the dermis and the connective tissue can be found, also with variable thickness. The dermis is the layer where the HA is positioned. Here is where the increase in volume happens, which has an impact on the layers above achieving a filling or smoothing of the wrinkle.

\section{Analysis of the expressive quality of the face}

A last evaluation is the quality of the facial expression. This evaluation has to happen with the analysis of the static and dynamic mimic activity. Each face is unique because of some important characteristics: the mimic, the skeletal muscle activity of the face and the neck, the head posture, the look, and the smile (the heart of the face).

\section{Surgical procedure: how and where}

The filler procedure is extremely simple and it only requires easy injections technique knowledge. Dentists are the best specialists in this field. A dentist, generally, performs dozens of injections everyday; probably thousands every year. For a dentist, an injection is a very familiar act.

The layer where the filler injection happens is, in 


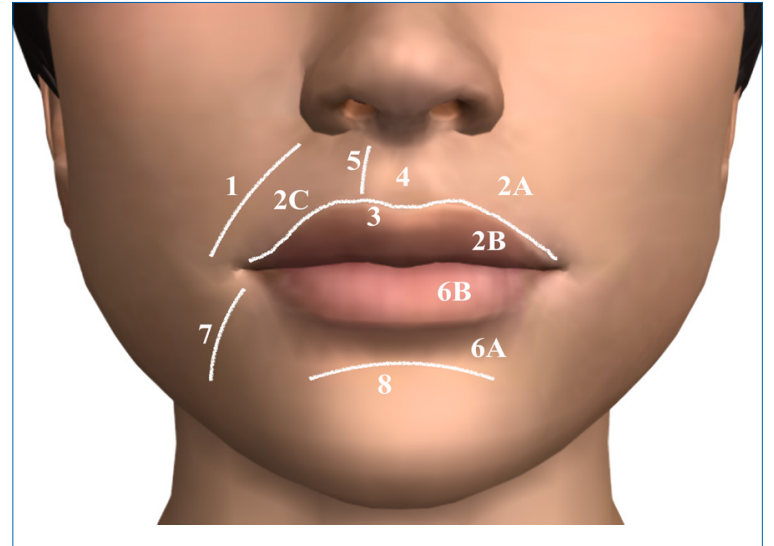

Figure 5. Aesthetic sub regions of the lip and perioral region. The perioral region is subdivided in at least ten sub regions with very different characteristics from one another and which require different therapeutic approaches. The main aesthetic sub regions of the lip are: the naso-labial fold (1), the white upper lip (2A), the red upper lip or upper vermillion (2B), the lip white roll (2C), Cupid's bow (3), the philtrum (4), philtrum's pillar (5), the white lower lip (6A), the red lower lip or the lower vermillion (6B), the labio-mandibular fold or puppet fold (7), and the labio-mental fold (8). Each one of these areas has particular anatomic characteristics: skin, subcutaneous tissues, muscles, fat, movements and mimic. The therapeutic options will be different for each different area.

Drawn by Aldo Zupi using ZygoteBody ${ }^{\mathrm{TM}}$ 3D Anatomy Viewer. Zygote Media Group Inc., American Forks, UT

the majority of the cases, the dermis. Within the dermis, the specialist can choose to use the superficial portion just below the epidermis, or a deeper portion, above the subcutaneous fat. The dermis has variable thickness depending on the anatomic area, the age and the degree of aging. The same happens in the epidermis. The skin can have minimum thickness in areas such as the periorbital one where it does not go over a millimetre or it can get to a few centimetres in areas such as the back or in areas subject to constant friction. However, there are general parameters that can be applied safely in all situations.

The depths in which we act can be divided in two layers: a superficial layer, generally 1-2 millimetres deep, and a deeper layer, usually never superior to 5 millimetres. The injection depth depends on the depth of the flaw. Small superficial wrinkles must be treated with superficial injections and with small quantities of material. If the line is deeper, the injection will need to be deeper too, as the quantity of skin to lift is bigger and wider. Even deeper is the area of injection for deep and not elastic wrinkles. A larger amount of material is required and the surface of the tissue to lift is wider. This is the first rule to follow to choose the right depth where to operate. The second rule is just as simple. Each area of the face has skin of constant thickness and, therefore the dermis can be found at a known depth.

We can easily subdivide three areas in which the skin is usually thin. In these areas, we will hardly go at a depth greater than 1-2 $\mathrm{mm}$. This applies especially to the so-called "white roll" of the lip. It is an important area because it will almost always be treated in our patients. To areas with thin skin oppose areas with thick skin. In these areas, generally, we inject at least at 2-3 $\mathrm{mm}$ of depth and in some cases even deeper. It is important to remember that almost the whole perioral region has a relatively thick skin and sometimes, when facing deep and "ancient" wrinkles, it is necessary to go very deep. We must always associate the concept of stickiness or density or reticulation of the HA used to the concept of depth. This way, the tissues will be "lifted" more naturally.

How should the HA filler be placed? A dentist is used to inject anaesthetics or other drugs. The technique is exactly the same. Once, the needle has been inserted and we have reached the desired depth, we will inject the quantity of filler we believe is right. The general rule is to usually under dose the injection. A correction, in fact, is always possible. On the other hand, the "subtraction", even if possible, is a lot more complicated.

Anyway, we will inject the quantity of HA desired in small spots along the wrinkle or the line we want to increase. The distance between spots is not very important. We can add material where and when we want if necessary and, if required, we could use the same site of injection. This way, with small and aimed corrections, we will achieve to fill or lift a wrinkle. The "spot technique" allows an extremely precise correction. However, it requires, patience and precision.

For those ... in a hurry, the linear technique consists in the injection of a "strip" of HA at the bottom of the wrinkle or along the line we want to increase. The technique is very simple. You will need to penetrate in the skin at an angle of about $45^{\circ}$ for the necessary depth. As we know, the depth can be of just a few millimetres (1 or 2) or even half a centimetre or more. Once we have reached the desired depth, we will move the needle until it is parallel to the skin. We will proceed along the line we want to fill up for the whole length of the needle. At this point we can start to inject the filler and, at the same time, we retract the needle. In this way, we release a strip of HA like the trail of a plane or of a boat, which will fill the line or wrinkle. Like in the "spot technique", we can go back to the same area as many times as we think it is necessary, lengthening or increasing the volume of the strip.

Below, are briefly mentioned the techniques usually used for the common imperfections of the face are briefly mentioned (labial wrinkles, thin lips, malar region and crow's feet).

The labial wrinkles are formed around the mouth and generally have a vertical movement. They are usually the result of mimic and aging. This imperfection is usually known as "barcode". Different factors, such as smoking can speed up the formation 
and increase the entity. The HA efficiently fills these wrinkles up and can get rid of the imperfection. The filling can happen for each single wrinkle or treat the whole white upper lip with a technique called "fan".

Thin lips are a congenital imperfection, genetically determined. They are usually very unpopular among women, as today's standard of beauty expects full lips. Dermal fillers allow an appropriate correction. The HA, makes the lips fleshier, via the infiltration of the correct quantity. The infiltration happens at different depths depending on the treated area and the volumes are gradually "redesigned". Thin lips are complex to correct and it is best to make this corrections in several steps. The HA is fully resorbable; this eliminates the fear of error for "excess". Anyway it is always advisable the search for a natural effect and not the "Hollywood" effect.

Less pronounced cheekbones, or anyway the physiological reduction of their volume, flattens the look of the face giving an older appearance. The infiltration of HA allows, in a relatively easy way, to increase the volume of the middle third making the face "sharper" and younger. This area, however, requires the use of a more dense or reticulated HA filler and its placement in layers "unusually" deeper. The so-called crow's feet are a common imperfection in both men and women. Even though they add 'depth and interest' to the eyes and look, they are not very much loved, especially by women. The correction is quite complex because of the extreme thinness of the skin, which can determinate the creation of visible "cords" (anyway reversible). In addition, the continued contraction of the muscular mimic decreases the effect of the correction. Therefore, the ideal treatment would be a combination of botulinum toxin and dermal filler. The HA must be injected very superficially and in extremely "controlled" quantities along the main lines. In this case, too, we have to follow the golden rule of not exceeding and eventually subdividing the treatment in several steps. It should not be forgotten that the injections of HA are not absolutely painless. In same areas, such as the lips, the majority of patients who had fillers feel a sense of burning or discomfort during the procedure. To avoid it, it is advisable to anesthetise the area, which is going to be treated. It is possible to do so with topical anaesthetic cream (usually with lidocaine) or with an injection in the oral vestibule (usually with mepivacaine without vasoconstrictor).

\section{REFERENCES}

1. Lubbock J. BrainyQuote.com, Xplore Inc [Internet]. 2016 [updated 2016; cited 2016 Aug 7]. Available from: http://www. brainyquote.com/quotes/authors/j/john_lubbock.html.

2. Treccani.it Enciclopedie on line [Internet]. 1934 [updated 2015; cited 2016 Aug 7]. Available from: http://www.treccani.it/ enciclopedia/avebury-sir-john-lubbock-barone/.

3. Sandoval LF, Huang KE, Davis SA, Feldman SR, Taylor SL. Trends in the use of neurotoxins and dermal fillers by US physicians. J Clin Aesthet Dermatol 2014;7(9):14-19.

4. American Society of Plastic Surgeons. 2015 Complete plastic surgery statistics report [Internet]. 2016 [updated 2016; cited 2016 Aug 15]. Available from: https://www.plasticsurgery.org/

\section{Conclusion}

The treatment of face imperfections with HA filler is a simple procedure, relatively painless and virtually free of complications and side effects (Tab. 3). It requires deep knowledge of the face anatomy and its tissues, understanding of the skin physiology, excellent knowledge of injection techniques, ability to empathise with the patients and aesthetic sensibility.

All dentists who have had some sort of dermal filler training are aware of the reason because dentists can and should perform these treatments. Luckily, a constantly increasing number of dentists apply to theoretical and/or practical courses of dermal filler. This tendency is creating more and more professionals who have great knowledge of facial anatomy with its skeletal, muscular, vascular and nervous structure. In addition, these specialists master the injection technique better than anyone else.

The HA is just a different substance to inject. The dentist only has to learn the different pressure and speed in a few minutes and a few attempts.

If the dentist knows anatomy, the physiology and aesthetic parameters of the face better than any other specialist, is there a more qualified specialist to evaluate the relation between lips and teeth? Or the changes of tissues and perioral volume during the smile? Is there another specialist who works with the face, or at least the portion between the cheekbones and the chin, every single day during his professional career?

Is there another specialist who, daily, makes aesthetic choices, which can be immediately evaluated by the patient? If the dentist has taken a serious and complete dermal filler training, is there a specialist who can offer a better cosmetic treatment to that indivisible unity constituted by face and smile? There are many complex treatments performed with $\mathrm{HA}$ in anatomic regions and tissues, which have nothing to do with the smile and face. No dentist would have dreamt to perform such treatments.

But, when the treatment of the tissue aims to complete the smile, a dentist with aesthetic sensibility, cannot limit himself to just be the doctor of the teeth. He must take responsibility to give or return harmony and health (the sum of which is beauty) to the faces of his patients.

\section{Acknowledgements}

The author declare no conflict of interest related to this study. There are no conflicts of interest and no financial interests to be disclosed.

Documents/news-resources/statistics/2015-statistics/plastic surgery-statistics-full-report.pdf.

5. Raoof N, Salvi SM. Self-injection of dermal filler: an underdiag nosed entity? Br J Dermatol 2015; 172(3):782-783.

6. Ballin AC, Brandt FS, Cazzaniga A. Dermal fillers: an update. Am J Clin Dermatol 2015;16(4):271-283.

7. Greene JJ, Sidle DM. The hyaluronic acid fillers: current understanding of the tussue device interface. Facial Plast Surg Clin North Am 2015:23(4):423-432.

8. Alberts B, Johnson A, Lewis J, Raff M, Roberts K, Walter P. Molecular Biology of the Cell. Fourth ed., New York, NY: Garland Science; 2002. 
9. Landau M, Fagien S. Science of hyaluronic acid beyond filling: fibroblasts and their response to the extracellular matrix. Plast Reconstr Surg 2015;136(5Suppl):188-195.

10. Balazs EA, Denlinger JL. Clinical uses of hyaluronan. Ciba Foundation Symposium 1989;143:265-275

11. Gold MH. Use of hyaluronic acid fillers for the treatment of the aging face. Clinical Interventions in Aging 2007;2(3):369-376.

12. Funt $D$, Pavicic T. Dermal fillers in aesthetics: an overview of adverse events and treatment approaches. Clin Cosmet Investig Dermatol 2013; 6:295-316.

13. American Academy of Facial Esthetics. Dentists doing Botox? It's about time! [Internet]. 2014 [updated 2014 Jul 14; cited 2016 Aug 7]. Available from: https://www.facialesthetics.org/ blog/dentists-botox-time.

14. Costa E, Di Gioia M. Analisi facciale. In: Costa E, editor. Estet ica dei tessuti orali e periorali in odontoiatria. Parma, Italy: Acta Medica Edizioni; 2014

15. Yarbus AL. Eye movements and vision. New York, NY: Spring er Science+Business Media; 1967

16. Beagley J, Gibson IM. Changes in skin condition in relation to degree of exposure to ultraviolet light. Perth: School of Biology, Western Australian Institute of Technology, 1980.

17. Hatzis J. The wrinkle and its measurement - a skin surface profilometric method. Micron 2004;35(3): 201-219.

18. Glogau RG. Aesthetic and anatomic analysis of the aging skin. Semin Cutan Med Surg 1996,15(3): 134-138.

\section{Aldo ZUPI \\ MD, DDS, Msci, PhD \\ Libera Università Internazionale del Benessere, Rome, Italy

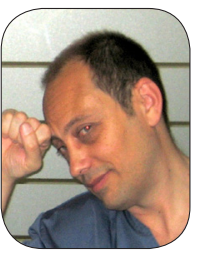

Maxillofacial surgeon with expertise in oral surgery and facial aesthetic medicine. For about three decades, he has worked as consultant and teacher for universities, hospitals, companies, and practitioners in Europe and United States. He works closely with dental and cosmetic manufacturers as a clinical researcher in developing new products and techniques. He is the author of more than one hundred scientific publications in national and international peer-reviewed journals. Graduated with honours in Medicine and Surgery; Specialist in Maxillofacial Surgery; awarded a PhD in Orbit and Maxillofacial Pathology at the "Federico II" University (Naples, Italy) and at the "Thomas Jefferson" University (Philadelphia, PA); Master in Forensic Odontology (Florence, Italy); Master in Perioral Tissues Aesthetic (Verona, Italy). For the last years, his interest has been lying in facial rejuvenation and oral regenerative surgery.

\section{Ouestions}

\section{The most used dermal filler is:}

$\square$ a. collagen;

ab. hyaluronic acid;

$\square$ c. polylactic acid;

$\square$ d. calcium hydroxylapatite.

\section{Facial filler are usually injected in:}

Da. subcutaneous fat;

b. keratinized layer of the skin;

ac. facial muscles;

ad. dermis.

\section{The classification of Glogau permits a clinical assessment of:}

$\square$ a. wrinkles;

b. facial muscles activity;

$\square$ c. type of skin;

$\square$ d. skin fototype.

\section{The facial soft tissue examination is correctly performed in:}

口a. frontal view;

b. lateral view;

c. frontal and lateral view;

$\square$ d. frontal, oblique, and lateral view. 